\title{
ÁCIDOS ORGÂNICOS NA SOLUÇÃO DE UM GLEISSOLO SOB DIFERENTES SISTEMAS DE CULTIVO COM ARROZ IRRIGADO(1)
}

\author{
Humberto Bohnen ${ }^{(2)}$, Leandro Souza da Silva ${ }^{(3)}$, Vera Regina \\ Mussoi Macedo(4) \& Elio Marcolin(4)
}

\begin{abstract}
RESUMO
O alagamento do solo para o cultivo do arroz irrigado promove condições anaeróbias que favorecem a produção de ácidos orgânicos de cadeia curta, os quais podem ser tóxicos para a cultura. Entretanto, a quantidade produzida destes ácidos depende, dentre outros fatores, do sistema de manejo empregado para o cultivo do arroz. Para avaliar a formação de ácidos orgânicos durante o cultivo do arroz irrigado nos sistemas: convencional, semeadura direta e prégerminado sobre resíduos de azevém, foram instalados coletores de solução do solo em duas profundidades $(2,5$ e $5,0 \mathrm{~cm})$ em parcelas de campo e retiradas amostras da solução do solo aos 3, 5, 9, 11 e 17 dias de alagamento. Nestas amostras, foram determinados os teores dos ácidos: acético, butírico e propiônico por cromatografia gasosa. Independentemente da profundidade de coleta, os maiores teores dos três ácidos avaliados ocorreram no sistema de semeadura direta, em comparação com o sistema convencional e pré-germinado. Entretanto, as diferenças significativas entre os sistemas perduraram, no máximo, até os primei ros 11 dias de alagamento. Teores mais el evados de áci dos orgânicos foram encontrados aos $5,0 \mathrm{~cm}$ de profundidade em comparação com $2,5 \mathrm{~cm}$ em todos os sistemas, com picos no quinto dia de alagamento. 0 ácido acético foi o ácido produzido em maior quantidade, independentemente do sistema de cultivo de arroz.
\end{abstract}

Termos de indexação: ácidos: acético, butírico e propiônico; sistemas: convencional, pré-germinado e semeadura direta, fermentação, decomposição anaeróbia.

\footnotetext{
(1) Trabalho apresentado como resumo na IV Reunião Sul-Brasileira de Ciência do Solo, em Porto Alegre (RS), de 14 a 16 de outubro de 2002. Recebido para publicação em agosto de 2003 e aprovado em fevereiro de 2005.

(2) Engenheiro-Agrônomo, PhD., Consultor do Instituto Rio Grandense do Arroz - IRGA Estação Experimental do Arroz. CEP 94930030 Cachoeirinha (RS). E-mail: humbertobohnen@ul.com.br

(3) Professor Adjunto do Departamento de Solos, Universidade Federal de Santa Maria - UFSM. CEP 97105-900 Santa Maria (RS). E-mail: leandro@smail.ufsm.br

(4) Pesquisador do IRGA. E-mail: solos-eea@irga.rs.gov.br
} 


\title{
SUMMARY: ORGANIC ACIDS IN THE SOIL SOLUTION OF A GLEY SOIL CROPPED WITH LOWLAND RICE UNDER DIFFERENT SYSTEMS
}

\begin{abstract}
The production of short-chain organic acids is favoured by anaerobic conditions in flooded soil during ricecultivation and they can betoxic for the crop. However, theamount of acids formed depends on thesystem used for thericecultivation. In order to measure the amount and type of organic acids formed in three different systems (conventional tillage, notillageand pregerminated planting), soil solution samples werecollected from two depths (2.5 and $5.0 \mathrm{~cm}$ ) after 3, 5, 9, 11, and 17 days of flooding. The soil sol utions wereanalysed for acetic, butyric and propionic acids by gas chromatography. Acid concentrations at both depths were higher in the no-tillage system, but si gnificant differences were only observed during the first 11 days of flooding. I $n$ all threesystems, higher organic acid concentrations were detected at a depth of $5.0 \mathrm{~cm}$ than at $2.0 \mathrm{~cm}$, and they peaked at the $5^{\text {th }}$ day of flooding. Acetic acid was produced in higher concentration than propionic and butyric acids in all three rice cultivation systems.

Indexterms: acetic, butyric and propionicacids; conventional tillage, pre-germinated planting no tillage, systems; fermentation; anaerobic decomposition.
\end{abstract}

\section{INTRODUÇÃO}

Com o alagamento do solo e esgotamento do oxigênio mol ecular, inicia-se um processo anaeróbio de decomposição dos restos culturais, com formação de substâncias orgânicas que podem ser tóxicas para as plantas, dependendo da sua qualidadeequantidade (Ponnamperuma, 1972). Dos compostos formados pel o metabol ismo anaeróbio, destacam-se os ácidos orgânicos alifáticos de cadeia curta, tais como: o acético, o propiônico e o butírico (Stevenson, 1967), que têm sido detectados em sol os do Rio Grande do Sul utilizados para o cultivo de arroz sob alagamento (Sousa, 2001). O ácido acético tem sido encontrado em maiores concentrações, seguido do propiônico e do butírico (Camargo et al., 2001; Sousa 2001).

De maneira geral, os ácidos orgânicos de cadeia curta causam danos principalmente ao sistema radicular, reduzindo seu crescimento e prejudicando o estabel ecimento de plântulas (Rao \& Mikkelsen, 1977; Camargo et al., 1993; Sousa, 2001; Agostinetto et al., 2001). Segundo Camargo et al. (2001), os ácidos orgânicos provocam efeitos não só sobre a germinação de sementes, alongamento radicular e matéria seca de raízes, peso e altura de plântulas, mas também na absorção de nutrientes. Também já foi constatado que estes ácidos podem ser tóxicos para as plantas de arroz na concentração de apenas um milimol por litro (Rao \& Mikkelsen, 1977).

Os ácidos orgânicos são produzidos pelos microrganismos anaeróbios do solo e, dessa forma, os fatores que influem na atividade microbiana no solo devem alterar a produção desses ácidos e a conseqüente liberação para a solução do solo, com reflexos no efeito tóxico às plantas. Segundo Neue et al. (1997), temperaturas entre 30 e $35^{\circ} \mathrm{C}$, solos com alta fertilidade e pH próximo da neutralidade são as condi ções que mais favorecem a decomposição da maioria dos resíduos culturais presentes no solo. Entretanto, a quantidade e a forma de distribuição dos resíduos culturais, proporcionadas durante o preparo do sol o, dependendo dos diferentes sistemas de cultivo de arroz, também devem influenciar o processo de decomposição dos resíduos e, conseqüentemente, as concentrações de ácidos produzidas. Os efeitos da quantidade de resíduos orgâni cos sobre as quantidades deácidos produzidos já são bem conheci dos na literatura (Camargo et al ., 1993; Camargo et al., 2001; Sousa, 2001). Já os efeitos da disposição do resíduo no solo foram inicial mente avaliados por Sousa (2001) em casa de vegetação, indicando sua importância para a determinação das quantidades de ácidos produzidas em diferentes sistemas de cultivo.

O arroz irrigado pode ser cultivado sob diferentes formas (IRGA, 2001). No sistema convencional, ocorre o preparo do solo com total revolvimento da camada superficial e entrada de água somente 20 a 40 dias após a semeadura. No sistema prégerminado, o sol otambém érevolvido, mas a entrada de água ocorre simultaneamente ao preparo. J á no sistema de semeadura direta, os resíduos culturais permanecem na superfície, onde é feito apenas um sulco para a semeadura, ea entrada de água ocorre de maneira semel hante à do sistema convencional . Em cada uma destas situações, o material vegetal do cultivo anterior ao arroz é disposto de diferentes formas e permanece sob diferentes graus de oxidação dependendo da mobilização ou não do solo e do momento do alagamento da lavoura, conforme o sistema de cultivo adotado pelo produtor. Além disso, estes três diferentes sistemas de cultivo proporcionam condições distintas à intensidade do processo de oxirredução que ocorre com o alagamento dosolo e, dessa forma, devem influenciar significativamente a produção de ácidos orgânicos.

Considerando seus efeitos sobre o estabel ecimento da cultura do arroz irrigado, o objetivo destetrabal ho foi avaliar a concentração dos ácidos orgânicos de cadeia curta na solução do solo de acordo com os 
sistemas de cultivo do arroz, em duas profundidades e ao longo do tempo de alagamento do solo.

\section{MATERIAL E MÉTODOS}

O experimento foi realizado na Estação Experimental do Arroz-EEA do Instituto Rio Grandensedo Arroz-IRGA, municípiode Cachoeirinha (RS), de outubro de 2001 a março de 2002. Utilizouse um experimento de campo com três sistemas de cultivo de arroz irrigado: convencional, prégerminado e semeadura direta que vinha sendo realizado por sete anos em um Gleissolo Háplico Ta distrófico (E mbrapa, 1999). O delineamento experimental foi em blocos ao acaso com três repetições. Cada parcela experimental apresentava uma área de $1.200 \mathrm{~m}^{2}$ separadas entresi com taipas.

Durante o período de inverno de 2001, toda a área experimental foi mantida com azevém, o qual foi dessecado com glyphosate (Roundup ${ }^{\circledR}$ na dosagem de $5 \mathrm{~L} \mathrm{ha-1}$ ) antes do cultivo do arroz. A quantidade de massa de azevém acumulada na superfície do solo após sua dessecação foi de 3,5 $\mathrm{Mg} \mathrm{ha}^{-1}$, em média, para os três sistemas. Em 19/11/2001, em toda a área foi semeado o cultivar de arroz IRGA 422CL na densidade de $120 \mathrm{~kg} \mathrm{ha}^{-1}$, em linhas espaçadas entre si com 17,5 amea lanço para osistema pré-germinado. $\mathrm{O}$ arroz foi adubado com $280 \mathrm{~kg} \mathrm{ha}^{-1}$ da fórmula 220-20 ( $N, \mathrm{P}_{2} \mathrm{O}_{5}$ e $\left.\mathrm{K}_{2} \mathrm{O}\right)$ na semeadura e com uréia em cobertura nas dosagens equivalentes a $100 \mathrm{~kg} \mathrm{ha}^{-1}$ de $\mathrm{N}$, quando o arroz encontrava-se no estádio V4 e $40 \mathrm{~kg} \mathrm{ha}^{-1}$ de N no estádio V8.
Após a semeadura do arroz, mas antes da entrada da água, foram enterrados no solo dispositivos para a coleta da solução do solo em um ponto aleatório dentro de cada parcela. Os coletores foram compostos por tubos de PVC de $25 \mathrm{~mm}$ de diâmetro por $4 \mathrm{~cm}$ de comprimento com as extremidades cobertas com tela de nylon com malha de $0,1 \mathrm{~mm}$ (Figura 1). Dois destes coletores foram presos em um outro cano dePVC de $25 \mathrm{~mm}$ de diâmetro e $60 \mathrm{~cm}$ de comprimento para serem enterrados no solo de modo que ficassem na profundidade de 2,5 e $5,0 \mathrm{~cm}$. $\mathrm{Na}$ parte central do coletor, foi afixado um tubo de vidro que se estendeu até à superfície do sol o com a abertura da extremidade superior fechada com resina desilicone para impedir a difusão de oxigênio para o interior do tubo. Dezoito dias após a emergência do arroz, foi realizado o alagamento das parcelas com a aplicação de uma lâmina de água de aproximadamente $10 \mathrm{~cm}$ de profundidade.

Aos 3, 5, 9, 11 e 17 dias de alagamento, foram extraídas amostras da sol ução do solo (entre as sete e dez horas da manhã) nos três sistemas de cultivo por meio de sucção usando uma seringa com agulha inserida na extremidade superior do tubo de vidro. Em todas as coletas, foi medida a temperatura do solo aos $5 \mathrm{~cm}$ de profundidade, que variou apenas de 21 a $24^{\circ} \mathrm{C}$ durante o período avaliado, o que mostra a pouca interferência da variação da temperatura do solo na produção dos ácidos nesse período. Após a extração de aproximadamente $15 \mathrm{~mL}$ desolução, as amostras foram imediatamente filtradas com filtro Versapor ${ }^{\circledR}$ de $0,2 \mu \mathrm{m}$ e uma alíquota de $5 \mathrm{~mL}$ da solução foi colocada em frascos

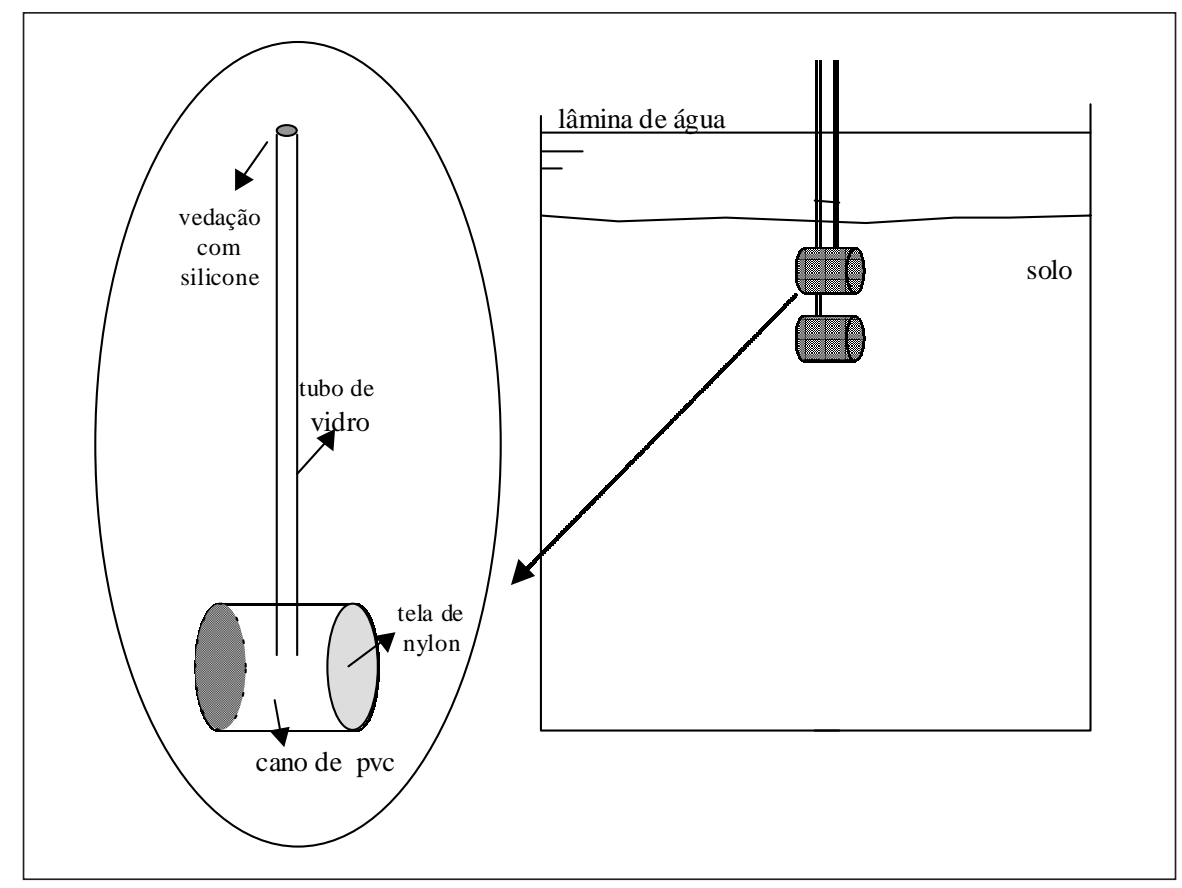

Figura 1. Representação esquemática do sistema de coleta da solução do solo. 
de vidrojuntamente com ácido fórmico $(0,3 \mathrm{~mL})$ para manter um pH menor que 2,0, sendo os frascos hermeticamentefechados para conservar as amostras até à determinação dos ácidos em laboratório.

Nestas amostras, foram analisadas as concentrações dos ácidos: acético, propiônico e butírico por cromatografia gasosa nos laboratórios do I PHUFRGS, em aparel ho Varian 3700 com detector de ionização de chama e col una empacotada de 0,90 m de comprimento e $0,2 \mathrm{~cm}$ de diâmetro interno, com fase estacionária de 0,3\% de Carbowax 20M e 0,1 \% de $\mathrm{H}_{2} \mathrm{PO}_{4}$ em Carbopaq C (60-80 mesh), conforme procedimento descrito por Sousa et al. (2002).

Os resultados foram anal isados estatisticamente por meio da análise de variância $(P<0,05)$, considerando o delineamento completamente casualizado. Os tratamentos foram arranjados em fatorial considerando os três sistemas de cultivo de arroz $\mathrm{x}$ duas profundidades amostradas e 5 períodos de col eta das amostras. As médias das quantidades dos ácidos produzidos em cada sistema ao longo do tempo de avaliação foram comparadas pel o teste de Tukey $(P<0,05)$.

\section{RESULTADOS E DISCUSSÃO}

As concentrações dos três áci dos estudados foram significativamente maiores $(P<0,05)$ no sistema de semeadura direta do que no sistema convencional e no pré-germinado para as primeiras coletas (Figuras 2, 3e 4), apesar de o tipo ea quantidade de resíduo orgânico terem sido semelhantes nos três sistemas. I sto pode ser atribuído ao fato de terem as avaliações de ácidos produzidos ocorrido nos primeiros $5 \mathrm{~cm}$ de profundidade. Observou-se que, no sistema de semeadura direta, a palha permaneceu acumulada justamente na superfície do solo, enquanto nos dois outros sistemas ela foi misturada no perfil, em decorrência das operações de preparo, favorecendo a oxidação de parte do carbono em condições aeróbias e, ou, diluindo as quantidades dos ácidos formados em condições anaeróbias na camada em que o sol o foi mobilizado.

Para todos os ácidos e profundidades, as concentrações máximas (69 e $118 \mathrm{mg} \mathrm{L}^{-1}$ para o acético, 18 e $34 \mathrm{mg} \mathrm{L}^{-1}$ para o propiônico e 7 e $14 \mathrm{mg} \mathrm{L}^{-1}$ para o butírico aos 2,5 e 5,0 cm respectivamente) ocorreram sempre ao redor do quinto dia de alagamento, apresentando, após 11 dias de alagamento, val ores semel hantes nos três sistemas (aproximadamente $8 \mathrm{mg} \mathrm{L}^{-1}$ para o acético, $1 \mathrm{mg} \mathrm{L}^{-1}$ para o propiônico e $0,5 \mathrm{mg} \mathrm{L}^{-1}$ para o butírico). A partir doterceiro dia dealagamento, os teores de ácido acético aos 5,0 cm de profundidade atingiram a concentração ao redor de $120 \mathrm{mg} \mathrm{L}^{-1}$, valor que tem sido relatado como suficiente para causar redução no crescimento radicular de plantas

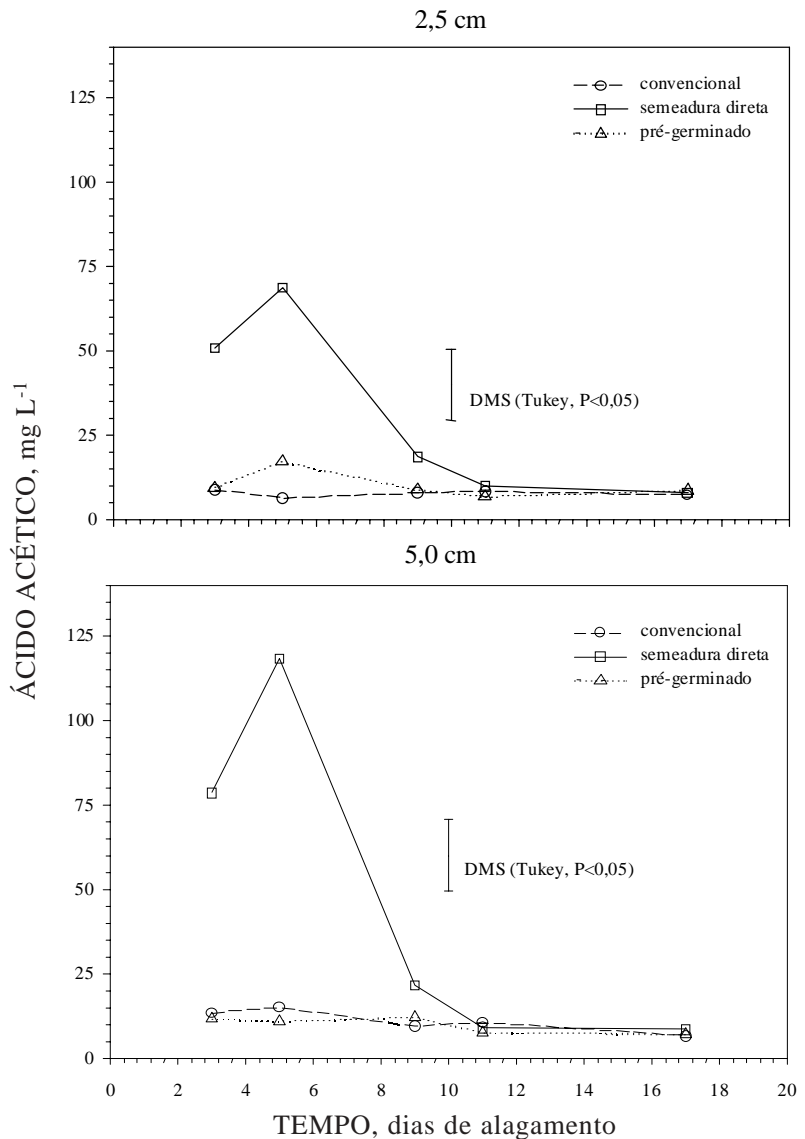

Figura 2. Concentração de áci do acéti co na solução de um Gleissolo, em duas profundidades (2,5 e $5,0 \mathrm{~cm})$, em três sistemas de cultivo de arroz durante 17 dias de alagamento do solo.

de arroz (Rao \& Mikkelsen, 1977; Camargo et al., 1995; Sousa \& Bortolon, 2002), sem considerar a possibilidade de interações com a presença dos outros ácidos. No trabalho de Sousa \& Bortolon (2002), reduções de até $30 \%$ no crescimento radicular e $18 \%$ em plântulas de arroz foram observadas em concentrações acima de $180 \mathrm{mg} \mathrm{L}^{-1}$ de áci do acético em solução nutritiva. Entretanto, segundo Wallace \& Whitehand (1980), é provável que exista sinergismo entre os ácidos, podendo ocorrer efeitos adversos às plantas quando existem simultaneamente ou mesmo quando a concentração individual é relativamente mais baixa do que a considerada tóxica para cada ácido isoladamente.

Dentre os ácidos, o acético foi liberado em maiores quantidades (Figura 2), conforme já tem sido relatado na literatura (Camargo et al., 2001; Sousa 2001), provavelmente por causa da decomposição mais lenta deste ácido em relação aos outros de cadeia mais longa (Watanabe, 1984), ou pela possibilidade de os ácidos: propiônico e butírico serem utilizados por alguns microrganismos para produção do ácido acético (Yoshida, 1975). A acetogênese (conversão deáci dos orgânicos com mais de dois carbonos para ácido acético) é uma etapa 


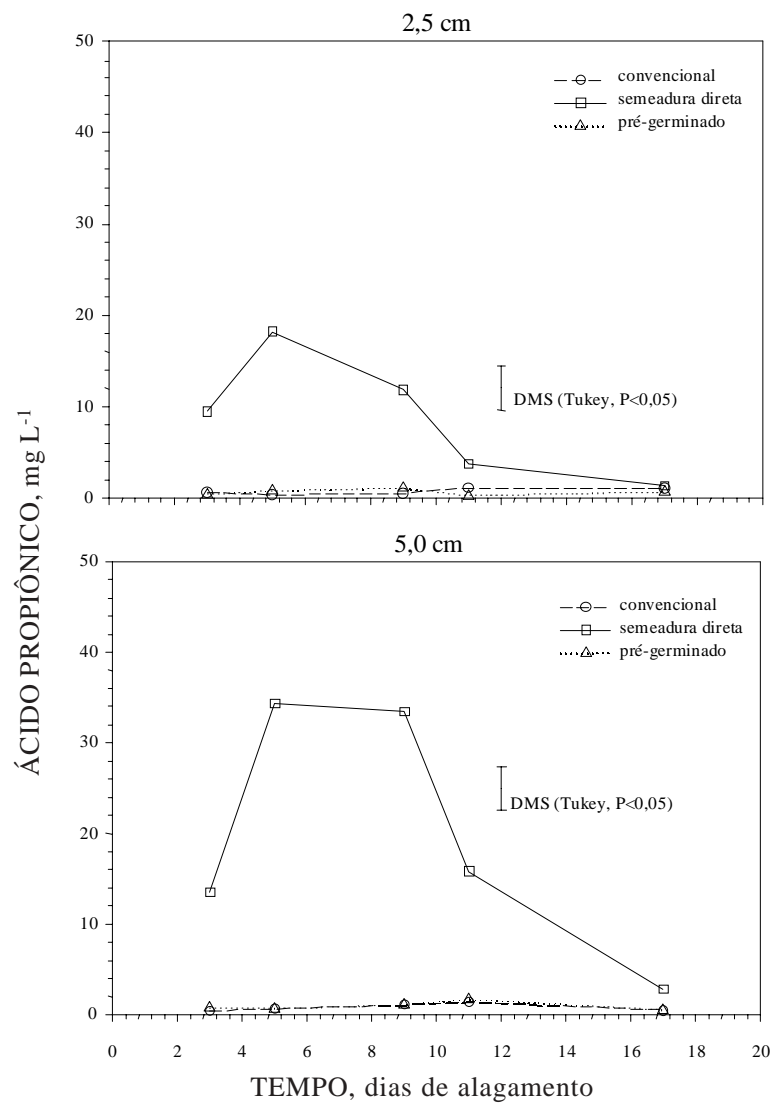

Figura 3. Concentração de ácido propiônico na solução de um Gleissolo, em duas profundidades $(2,5$ e $5,0 \mathrm{~cm})$, em três sistemas de cultivo de arroz durante 17 dias de alagamento do solo.

intermediária entre a produção de ácidos orgânicos e a formação de metano, pois não é possível que o ácido butírico e o propiônico sejam diretamente fermentados a metano. Sousa (2001), trabalhando em condições de casa de vegetação com dois sol os do Rio Grande do Sul (Planossolo e Plintossolo) e com a adição de resíduo de azevém na superfície do solo, encontrou concentrações máximas de ácido acético de até $1.000 \mathrm{mg} \mathrm{L}^{-1}$, e $300 \mathrm{mg} \mathrm{L}^{-1}$ para os ácidos propiônico e butírico, aproximadamente 14 dias de alagamento. Esses valores relativamente mais el evados podem estar relacionados com o fato de que os vasos não permitem a difusão dos ácidos no perfil do solo, o que deve ocorrer em condições de campo.

As concentrações dos três ácidos sempre foram maiores aos $5 \mathrm{~cm}$ de profundidade, quando comparadas com a col eta aos $2,5 \mathrm{~cm}$, especial mente para a semeadura direta, em que os restos culturais foram dispostos na superfície (Figuras 2 a 4). I sto deveu-se, provavelmente, às condições de menor disponibilidade de oxigênio molecular nesta profundidade, que pode aumentar a intensidade das reações de redução ea produção deáci dos orgânicos, independentemente da distribuição dos resíduos das plantas. Outra possibilidadepara estecomportamento está relacionada com o fato de que éjustamente aos
$5 \mathrm{~cm}$ de profundidade que se encontra a maior quantidade de raízes, as quais podem liberar compostos orgânicos de fácil decomposição pelos microrganismos do solo e que servem de matériaprima para a produção de ácidos orgânicos. É provável que em profundidades superiores a $5 \mathrm{~cm}$, mesmo no sistema de semeadura direta, os teores de ácidos sejam menores que os encontrados nas duas camadas avaliadas em virtude da menor disponibilidade de material orgânico, como já foi relatado por Sousa (2001).

Os ácidos, propiônico e butírico, acompanharam as oscilações temporais e espaciais do ácido acético, mas seus teores foram sempre mais baixos. A diminuição na concentração dos ácidos orgânicos após duas semanas de alagamento deveu-se, provavel mente, à conversão dos ácidos orgânicos a metano (Yoshida, 1975) como conseqüência das reações de redução no ambiente anaeróbio.

Outros estudos precisam ser efetuadas para determinar a produção deácidos orgânicos de cadeia curta em diferentes sistemas de cultivo de arroz irrigado com diferentes quantidades e tipos de resíduos, bem como seus reflexos sobre a

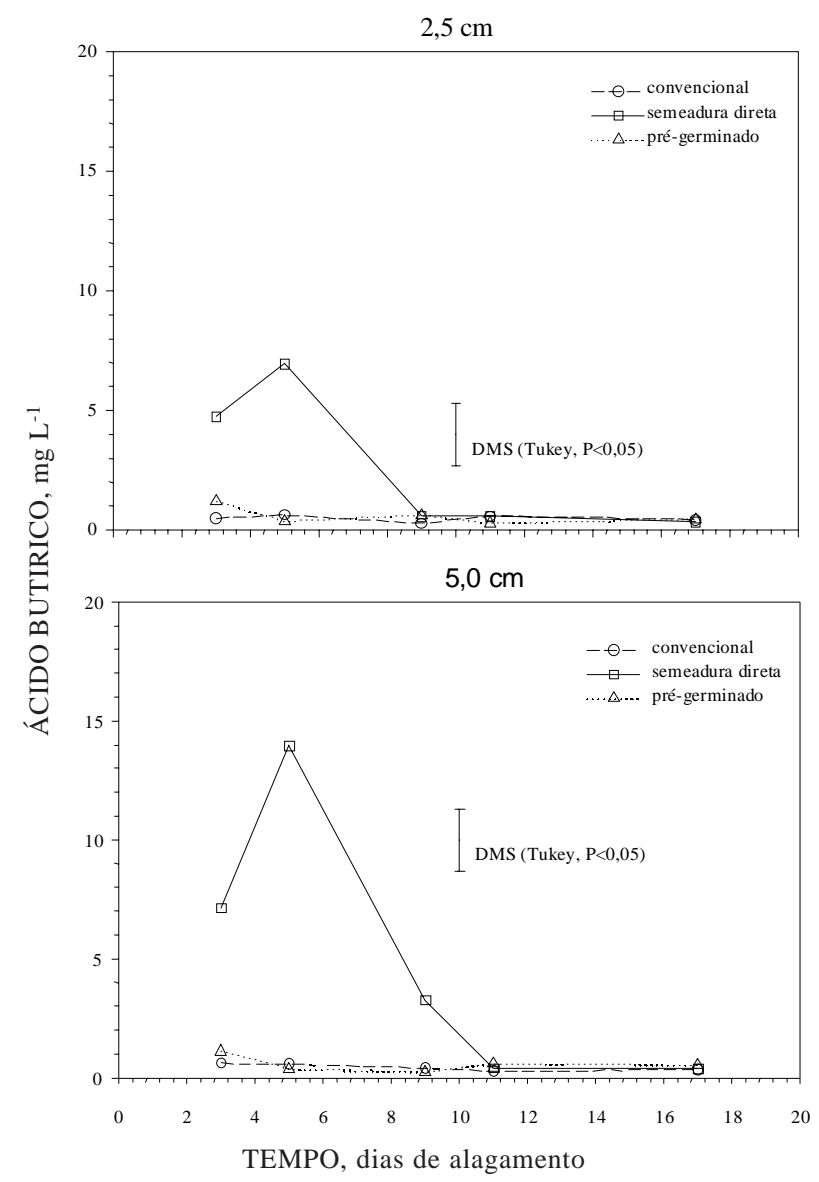

Figura 4. Concentração de ácido butírico na solução de um Gleissolo, em duas profundidades (2,5 e $5,0 \mathrm{~cm}$ ), em três sistemas de cultivo de arroz durante 17 dias de alagamento do solo. 
produtividade do arroz, a fim de se estabelecerem estratégias de manejo mais adequadas para minimizar seus efeitos tóxicos à cultura.

\section{CONCLUSÕES}

1. Nosistema de semeadura direta para o cultivo do arroz irrigado por inundação, foram produzidas maiores quantidades de ácidos orgânicos de cadeia curta, em relação às quantidades dos sistemas: convencional e pré-germinado.

2. O ácido acético foi produzido em maior quantidade do que o ácidos propiônico e o butírico, independentemente do sistema de cultivo do arroz.

\section{LITE RATURA CITADA}

AgOSTINETTO, D.; FLECK, N.G.; BALBINOT, A.A.; RIZZARDI, M.A.; COSTA, E.L.N.\& GUMA, J .M.C. Ácidos orgâni cos que se formam durante a decomposição da palha no sol o afetam os processos de germinação e de crescimento inicial das plântulas da cultivar de arroz IRGA-417. In: CONGRESSO BRASILEIRO DE ARROZ IRRIGADO, 2., Porto Alegre, 2001. Anais. Porto Alegre, Instituto Rio Grandense do Arroz, 2001. p.894.

CAMARGO, F.A.O.; SANTOS, G.A. \& ROSSIELO, R.O.P. Efeito dos ácidos acético e butírico sobre o crescimento de plântulas de arroz. Pesq. Agropec. Bras., 28:1011-1018, 1993.

CAMARGO, F.A.O.; SANTOS, G.A. \& ROSSIELO, R.O.P. Incorporação de palha de arroz em um gleissolo e efeitos no rendimento da cultura do arroz irrigado. Pesq. Agropec. Bras., 30:983-987, 1995.

CAMARGO, F.A.O.; ZONTA, E.; SANTOS, G.A. \& ROSSIELO, R.O.P. Aspectos fisiológicos e caracterização da toxidez de ácidos orgânicos voláteis em plantas. Ci. Rural, 31:523-529, 2001.
EMPRESA BRASILEIRA DE PESQUISA AGROPECUÁRIA EMBRAPA. Sistema brasileiro de classificação de solos. Brasília, 1999. 412p.

INSTITUTO RIO GRANDENSE DO ARROZ - IRGA. ArroZ irrigado: recomendações técnicas para oSul do Brasil. Porto Alegre, 2001. 128p.

NEUE, H.U.; GAUT, J .L. \& WANG, Z.P. Carbon in tropical wetlands. Geoderma, 79:163-185, 1997.

PONNAMPERUMA, F.N. Thechemical of submerged soils. Adv. Agron., 24:29-96, 1972.

RAO, D.N. \& MIKKELSEN, D.S. Effect of acetic, propionic, and butyric acids on young rice seedlings' growth. Agron. J ., 69:923-928, 1975.

SOUSA, R.O. Oxirredução em solos alagados afetada por resíduos vegetais. Porto Alegre, Universidade Federal do Rio Grande do Sul, 2001. 164p. (Tese de Doutorado)

SOUSA, R.O. \& BORTOLON, L. Crescimento radicular e da parte aérea do arroz (Oryza sativa L.) e absorção de nutrientes, em solução nutritiva com diferentes concentrações de ácido acético. R. Bras. Agroc., 8:231-235, 2002.

SOUSA, R.O.; PERALBA, M.C.R. \& MEURER, E.J . Short chain organic acid dynamics in solution of flooded soil treated with ryegrass residues. Comm. Soil Sci. Plant Anal ., 33:779787, 2002.

STEVENSON, F.J . Organic acids in soil. In: MCLAREN, A.D. \& PETERSON, G.H., eds. Soil biochemistry. Arnold, 1967. p.119-146.

YOSHIDA, T. Microbial metabolism of flooded soil. Soil Biochem., 3:83-122, 1975.

WALLACE, J .M. \& WHITEHAND, L.C. Adverse synergistic effects between acetic, propionic, butyric and valeric acids on the growth of wheat seedling roots. Soil Biol. Biochem., 12:445-446, 1980.

WATANABE, I. Anaerobic decomposition of organic matter in flooded rice soil. In: INTERNATIONAL RICE RESEARCH INSTITUTE. Organic matter and rice. Los Baños, 1984. p.237-258. 